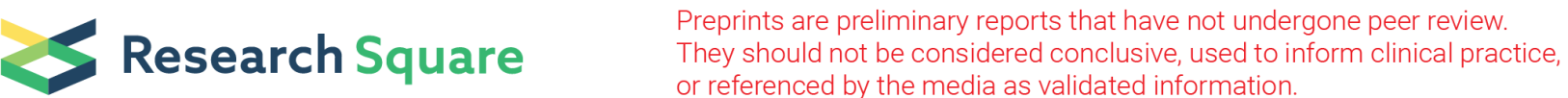

\section{Using the Medical Research Council Framework for the development of a communication partner training intervention for people with primary progressive aphasia (PPA): Better Conversations with PPA}

Anna Volkmer ( $\square$ a.volkmer.15@ucl.ac.uk)

University College London

Aimee Spector

University College London

Kate Swinburn

University College London

Jason D. Warren

University College London

Suzanne Beeke

University College London

\section{Research Article}

Keywords: Primary Progressive Aphasia, Speech and Language Therapy, Intervention, conversation, coproduction, consensus

Posted Date: February 24th, 2021

DOl: https://doi.org/10.21203/rs.3.rs-228838/v1

License: (c) (i) This work is licensed under a Creative Commons Attribution 4.0 International License. Read Full License 


\section{Abstract}

Background: Primary Progressive Aphasia (PPA) is a language-led dementia resulting in a gradual dissolution of language. PPA has a significant psychosocial impact on both the person and their families. Speech and language therapy (SLT) is one of the only available management options, and communication partner training (CPT) interventions offer a practical approach to identify strategies to support conversation. The aim of this study was to define and refine a manual and an online training resource for speech and language therapists to deliver CPT to people with PPA and their communication partners (CPs) called Better Conversations with PPA (BCPPA).

Methods: The BCPPA manual and training program were developed using the Medical Research Council framework for developing complex interventions. The six-stage development process included 1. Review of existing literature, 2. Consultation and co-production 3. Development of an initial draft 4. Review by a group of speech and language therapists, using consensus methods 5. Two focus groups to gather opinions of people with PPA and their families 6. Refinement.

Results: The BCPPA manual and training program comprises seven modules, and four CPT intervention sessions. Eight important components of CPT were identified in the consensus work undertaken with speech and language therapists, including use of video feedback to focus on strengths as well as areas of conversation breakdown. Three themes arose from the focus groups with people with PPA and their families 1) Timing of intervention, 2) speech and language therapists' understanding of types of dementia, and 3) Knowing what helps. Refinements to the manual included additional practice activities and useful strategies for the future.

Conclusions: Using the MRC framework to develop an intervention that is underpinned by a theoretical rationale based on a review of the literature, increases the likelihood of behaviour change. Codevelopment of the manual and training materials ensures the intervention will meet the needs of people with PPA and their CPs. Gathering further data from speech and language therapists and people living with PPA and their families to refine the manual and the training materials enhances the feasibility of delivering this in preparation for a phase II NHS-based randomised controlled pilot-feasibility study, currently underway.

\section{Background}

The number of people living with dementia worldwide continues to rise, estimated at around 50 million at present with nearly 10 million new cases each year ${ }^{1}$. Of these, perhaps a half a million people worldwide and several thousand in the United Kingdom have primary progressive aphasia (PPA): a group of language-led dementias associated with Frontotemporal Dementia and Alzheimer's disease ${ }^{2}$. PPA presents as an insidious dissolution of language skills with relative sparing of other cognitive functions ${ }^{2}$. At present there are three internationally recognised PPA variants; people with semantic variant (svPPA) experience a gradual loss of word meanings affecting both comprehension and naming, people with 
logopenic variant PPA (IvPPA) present with difficulties in word retrieval and processing of complex sentences, and people with non-fluent agrammatic variant PPA (nfvPPA) demonstrate effortful, distorted articulation of speech sounds (apraxia) and/or an agrammatism ${ }^{3}$. Each variant presents with a distinct neuroanatomical distribution of atropy and underlying neuropathology ${ }^{2,3}$. Though it constitutes only a small proportion of the total dementia burden, PPA is of disproportionate clinical importance because it tends to strike people in older midlife with devastating impact on occupational and social functioning and because it presents a number of unique challenges not well met by conventional models of aphasia and dementia management.

People with PPA report increasing social isolation and reduced confidence as a result of their worsening communication difficulties ${ }^{4}$. More than one third of people with PPA experience depression and symptoms of anxiety are not uncommon. These likely impact directly on reports of reduced quality of life amongst people with PPA ${ }^{5}$. Spouses of people with PPA report a long trajectory of change, even prior to diagnosis. This results in feelings of loss of relationship and meaningful social interaction, increasing dependency of their spouse with PPA on them for communication, and overwhelming responsibility ${ }^{6}$.

The research literature on speech and language treatment approaches for people with PPA is developing. The majority of research has focused on impairment-focused interventions that aim to maintain or improve the person's ability to use words ${ }^{7,8}$. Many people with PPA disengage from such naming therapies due to the frustration of practising individual words they will inevitably lose as the disease progresses ${ }^{9}$. More recently there has been a growing focus on functional communication interventions for PPA, which aim to support a person to execute an activity or participate in a life situation ${ }^{10}$. A systematic review of these diverse interventions identified two key shared components; building on existing strategies, and practising strategies with a communication partner ${ }^{10}$.

Despite barriers to therapy access, such as a lack of awareness of the role of the speech and language therapist in PPA, and restrictive service criteria, the number of people with this condition being referred to SLT is increasing ${ }^{11}$. In contrast to a research focus on naming therapies, in clinical practice speech and language therapists prioritise communication partner training (CPT) interventions for people with PPA and their communication partners (CPs) ${ }^{11,12}$.

CPT interventions for stroke and dementia have arisen from studies of conversation between people with communication disorders and their CPs. This research demonstrates that both people with dementia and aphasia draw on areas of retained strength, such as gesture, to maintain interactional flow ${ }^{13,14,15}$. Some CPs are seen to facilitate conversational interaction, for example through giving time, but can equally expose their partners' difficulties by using barrier behaviours, for example, test questions (to which they already know the answer, a pedagogic behaviour used with children). CPT interventions aim to change conversation behaviours, enhancing conversational skill and confidence, and reducing barriers to facilitate the flow of natural conversation ${ }^{16}$. CPT interventions result in improved quality of life and wellbeing for people with dementia, and improved competency in their $\mathrm{CPs}^{17}$. 
Many speech and language therapists report delivering CPT to people with PPA and describe using resources developed for stroke aphasia or brain injury related communication difficulties ${ }^{12}$. CPT has a growing evidence base in stroke aphasia 16,18 and delivers positive changes in the conversation skills of people with aphasia as well as their $\mathrm{CPs}^{19,20}$. However, CPT approaches in stroke aphasia are not designed to meet the needs of people with progressive communication difficulties. Currently there are only case study reports of CPT for people with PPA ${ }^{21,22}$. There is some suggestion of increased communicative effectiveness as a result, however, it is difficult to attribute these gains to CPT due to the fact that individuals were concurrently participating in additional interventions. Thus, there is a clinical need to develop a CPT intervention designed to meet the needs of people with PPA and their families $^{6,23,24}$.

To our knowledge there has been no specific research undertaken asking people with PPA and their families what interventions are important or need to be developed. People with PPA have written about their general experiences of SLT and the value of developing "a wide range of personalized strategies that continually evolve as the disease progresses" 25 . Spouses report a need to develop practical approaches to deal with communication difficulties and maintain a close bond with their loved ones ${ }^{6}$. These issues are more likely to be met by tailored interventions, that build capacity by helping them to adjust and reframe their communication over time ${ }^{6}$. Speech and language therapists themselves have identified a need to engage family who are motivated to understand how they can best support their loved ones ${ }^{26}$ Therefore, gathering ideas and contributions of people living with PPA, often described as Public Involvement $(\mathrm{PI})$, is important to ensuring an intervention will meet their needs. $\mathrm{PI}$ is defined by the UK Standards for $\mathrm{PI}$ as research that is carried out with members of the public rather than to them. These standards include ensuring that people are involved as early as possible and that participation is made accessible. The aim of this study was to work with people with PPA and their families, from the beginning, to co-produce a CPT intervention to meet their needs.

The Medical Research Council provide a framework for developing and evaluating complex interventions ${ }^{27}$. The guidance outlines the importance of preliminary development and testing of an intervention's procedures prior to piloting and evaluation. This paper therefore describes how the MRC framework was used to develop Better Conversations with PPA (BCPPA), a 4-session, manualised, CPT intervention to help people with PPA and their CPs to identify and practice strategies to reduce barriers (such as interjecting when a person may not have finished) and increase facilitators in conversations (such as giving more time). A manual and an online training resource for speech and language therapists, hosted on a life-learning platform at UCL, were developed to enable speech and language therapists to deliver the intervention. In line with stages 1 and 2 of the MRC Framework the underlying theory and proposed mechanisms of change for the BCPPA program will be described as well as primary research which informed the co-production of the manual and online training resource.

Aim 
To use the MRC framework for developing complex interventions to define and refine a manual and an online training resource for speech and language therapists to deliver BCPPA to people with PPA and their CPs.

\section{Methods}

Intervention development activities were based on phases one and two in the MRC framework for development of complex interventions ${ }^{27}$. This comprised six stages including 1. examination of existing literature, 2. consultation and co-production work, 3. development of an initial draft, 4 . consensus work with speech and language therapists, 5. focus groups with people with PPA and their families, 6 . Refinement of the BCPPA intervention and manual in preparation for the randomised controlled pilotfeasibility study. Figure 1 demonstrates how these activities map onto the MRC guidance. Intervention development also followed the GUIDED guidelines for reporting for intervention development studies ${ }^{28}$. Further patient and public involvement work undertaken to finalise outstanding training modules identified as supplementary to the RCT will not be discussed here. The first author, A.V., an experienced speech and language therapist, led all stages.

\section{Recruitment}

Consultation and co-production work (Stage 2): An opportunistic sample of people with PPA and their families, specialist speech and language therapists and neuropsychologists were invited to join the project steering group. A.V. emailed people who were known to her through clinical work, and asked the facilitator of the PPA branch of the Rare Dementias Support Group based at UCL

(https://www.raredementiasupport.org) to forward an invitation email to individuals in the support group, inviting them to participate.

Consensus work (Nominal Group Technique, NGT) with speech and language therapists (Stage 4): speech and language therapists were recruited to participate in the NGT consensus study through the RCSLT Dementia and Mental Health Clinical Excellence Network, of which A.V. was a committee member. The NGT was carried out at one of the Clinical Excellence Network meetings and advertised in the RCSLT clinical practice magazine (Bulletin) and via emails circulated to members two months prior to the study day taking place.

Focus groups with people with PPA and their families (Stage 5): People with PPA and their families who attend the PPA branch of the Rare Dementias Support Group at UCL were invited to participate in one of two focus group meetings held at an accessible venue on the university campus. The aim was to recruit eight people to each focus group, totaling 16 participants. To optimize opportunities for individuals with communication difficulties to contribute to discussion ${ }^{29}$, group numbers were capped at eight participants. Potential participants who responded to the advert were contacted by A.V. on the telephone to judge if they met the inclusion criteria of a) a diagnosis or possible diagnosis of PPA/relative with such a diagnosis, b) the ability to communicate to participate in a focus group $c$ ) see and hear well enough to 
participate d) English as their language of daily use. Potential participants were excluded if they had a) a history of brain lesion or major head trauma, b) major physical illness or disability which could impact on participation. criteria required.

\section{Examination of existing literature (Stage 1)}

Existing models of dementia, principles of applied Conversation Analysis (CA), behaviour change theory and frameworks for chronic disease self- management were explored. This informed the preliminary contents and focus of the intervention.

\section{Consultation and co-production work (Stage 2)}

Four people with PPA and their spouses, two expert speech and language therapists, a neuropsychologist and the group facilitator (A.V.) took part in 12 formal BCPPA public involvement (PI) steering group meetings. Work to co-produce the BCPPA intervention materials and training modules was informed by feedback from people with PPA who had previously received $\mathrm{CPT}^{30}$, research undertaken by A.V. ${ }^{10,11,12}$ and research into the BCA program for people with stroke aphasia ${ }^{31}$. In order to support communication, steering group members were informed of the topic for discussion in advance of each meeting and invited to contribute in advance, during or after meetings using verbal, written or visual means, e.g. bringing photos, drawing pictures or re-assembling draft materials.

\section{First draft of the manual (Stage 3)}

A draft of the BCPPA manual was developed using PowerPoint software. In order to upload these to the UCLeXtend website an online software package called Articulate was used to adapt the PowerPoint slides to an appropriate format. The work was undertaken with assistance from speech and language therapist researchers and four postgraduate researchers in speech and language sciences who were paid for their time.

\section{Consensus work (Nominal Group Technique) with speech and language therapists (Stage 4)}

Draft one of the manual was made available to a group of speech and language therapists, who were attending a Clinical Excellence Network study day. In order to gain an understanding of the clinical experiences and reality of speech and language therapists a qualitative research method was identified as appropriate. Speech and language therapists were encouraged to review the resource and pilot it with their clients. To ensure the BCPPA intervention reflected a consensus view of the most important components to include in a CPT intervention for people with PPA and their families a Nominal Group Technique (NGT) method was chosen. Given that many of the speech and language therapists participating in the study day had pre-existing professional relationships that could result in certain voices being represented over others in discussions, the NGT method was also chosen to provide opportunities to consider ideas and experiences equally, yet allowing for clarification and discussion prior to rating ${ }^{32}$. 
Six weeks prior to attending the study day speech and language therapists were sent an email inviting them to anonymously complete a 12-item feedback survey comprising all open questions (supplementary document 1), hosted online on the Google Forms platform. Survey questions were developed by A.V. in consultation with the steering group and included questions about speech and language therapists' experiences and views on the content and format of the manual.

The NGT meeting itself comprised a two-stage ranking process commencing with a 90-minute group session (stage one), followed by email consultation (stage two). Meeting facilitators (AV and SB) agreed the session plan and central question for discussion in advance (see supplementary document 2), in line with guidelines for conducting NGT meetings ${ }^{14}$. At stage two, results of the group session were circulated via email to all participants, providing information on scores and mean rankings for each item. As per guidelines for conducting NGT meetings ${ }^{32}$, items describing the same ideas from the two groups were merged, following discussion and agreement between A.V. and S.B. Participants were asked to reply via email identifying and ranking their top eight items from this list (by placing a number from 1-8 to reflect which is most important - 8 and least important - 1). Following NGT guidelines ${ }^{32}$, scores were tallied and mean rankings calculated to identify the top eight ranked items overall.

\section{Focus groups with people with PPA and their families (Stage 5)}

Two focus groups took place, to provide people with PPA and their families the choice of attending with or without partners. Discussion was guided by the question 'How can speech and language therapists support people with PPA to live well and maintain relationships?'. The focus groups were jointly facilitated by A.V., alongside volunteer student speech and language therapists from UCL (one per focus group). A topic guide was co-produced with the BCPPA steering group and attendees of the PPA branch of the Rare Dementia Support Group at UCL (see supplementary document 3).

Focus group discussions were video recorded and transcribed by UCL student speech and language therapists (using transcription guidance ${ }^{33}$ ). Given the researchers objectives to understand the lived experiences of people with PPA and their families, and gather opinions from them, qualitative methods employing a realist approach to reflexive thematic analysis was undertaken ${ }^{34,35}$. Initial codes were generated by systematically coding interesting features (phase 2), collating these into potential themes (phase 3) and reviewing them in relation to the coded extracts (phase 4). Potential themes were refined to generate definitions and names (phase 5), further inspected to identify and report any additional key elements (phase 6). In addition, to improve reliability of analysis, four speech and language therapist researchers with experience of thematic analysis independently extracted data from a randomly selected section of transcript, discussed and reached agreement on the coding of themes arising from the data.

\section{Refinement of the BCPPA manual (Stage 6)}

The BCPPA manual was refined based on work undertaken in stage 4 and 5 (Figure 1). 


\section{Results}

Examination of existing literature (Stage 1)

Existing literature comprising the bio-psychosocial model of dementia, applied CA, behaviour change theory and self-management and self-efficacy theory was examined.

\section{Bio-psychosocial model of dementia}

The bio-psychosocial model ${ }^{36}$ proposes that there are factors other than the organic causes of dementia that influence the nature and speed of deterioration in daily functioning. These include some factors that are fixed, such as PPA variant, that cannot be changed. The BCPPA manual therefore provides practice tasks, to maximise generalisation for people with svPPA, for whom this is more difficult than those with nfvPPA (insert ref to cadorio). Tractable factors, such as the way a CP interacts with a person with PPA, may be amenable to change and are directly targeted in the BCPPA intervention. Adaptive mechanisms used by the $\mathrm{CP}$, such as multiple questions or test questions, may result in the person with PPA feeling incompetent ${ }^{37}$. On the other hand, the use of gesture and enactment (whole body gesture and pantomime) by a person with PPA when they are having difficulty retrieving a spoken word ${ }^{38}$ could be $^{-1}$ described as an effective coping strategy. The BCPPA intervention seeks to take account of fixed factors whilst targeting tractable factors to support the dyad (person with PPA and their CP) achieve their potential function.

\section{Applied Conversation Analysis (CA)}

CA is an approach to the study of human social interaction through the analysis of spontaneous, naturally occurring talk ${ }^{39}$. A number of $\mathrm{CA}$ informed stroke aphasia intervention studies and clinical resources have been developed ${ }^{40}$ such as $\mathrm{SCA}^{18}$, SPPARC ${ }^{41}$ and $\mathrm{BCA}^{42}$. These have in common the analysis of video recordings of natural conversations between the person with aphasia and their $\mathrm{CP}$, and providing these as video feedback, as a foundation for targeting therapy ${ }^{40}$. The speech and language therapist (who typically delivers such an intervention) analyses 10-15 minute video-recorded interaction to identify behaviours resulting in conversational breakdown, known as barriers, and ways in which members of a dyad successfully resolve or circumvent troubles to maintain interaction, known as facilitators. The aim of video feedback is to increase awareness in one or both members of the dyad of the impact of their behaviours, and jointly agree on goals for therapy. Once the goals of therapy are agreed upon, a process of practice, through supported conversations, role play and reflection, is commonly employed ${ }^{40}$. The BCPPA intervention is informed by this well-described ${ }^{43}$, CA-underpinned approach to CPT.

\section{Behaviour change theory}

Recognising conversational barrier behaviours in video recordings of oneself and setting a goal to cease these, or adopt facilitative strategies instead, does not guarantee that a change in behaviour will occur ${ }^{44}$. 
Behaviour change theory, specifically the COM-B model ${ }^{45}$ accounts for an individual's behaviour change as the product of three equally weighted components namely Capability, Opportunity and Motivation. Researchers examined video recordings of CA-underpinned CPT being delivered to people with stroke aphasia and their $\mathrm{CPs}^{46}$ and used the $\mathrm{COM}-\mathrm{B}$ model ${ }^{45}$ to identify the essential change processes and the core procedures that serve them ${ }^{47}$. The BCPPA intervention incorporates the seven core mechanisms that have been identified as essential to behaviour change in a $\mathrm{CPT}^{46}$, specifically the processes to motivate change and those that embed changes (See supplementary material 4).

Self-management and self-efficacy

Central to self-management is the concept of the client as an active participant whose current status is influenced not only by diagnosis but by psychological responses and experiences. This implies interventions should address the ability to self-manage daily activities and the emotional journey, not just medical symptoms ${ }^{48,49}$. Taking action to accomplish a plan to self-manage their condition is more likely to succeed if a person has the confidence or self-efficacy to achieve it ${ }^{50}$. Self-efficacy is a mechanism that directs behaviour change, for if one feels in control of a behaviour it becomes easier to make a change to it ${ }^{50}$. Five core self-management skills and four key self-efficacy mechanisms have been highlighted for inclusion in speech and language therapist interventions with people with progressive communication difficulties ${ }^{49}$ and these have been considered in the development of the BCPPA intervention (see supplementary file 4).

\section{Consultation and co-production work with the steering group (Stage 2)}

Decisions made included:

1. Identification of seven subjects to form distinct training modules within the BCPPA program. Table 1 provides an overview of the learning objectives and how these were co-produced. The three modules required for the phase II NHS based randomised controlled pilot-feasibility study (Module 3: How to make a video, Module 4: What to target in therapy and Module 5: the BCPPA therapy) were prioritised for development over the four only needed for the future general release of the online BCPPA program. Table 2 provides an overview of the content of these three modules.

2. Development of a topic list, for Module 3: How to make a video, to support participants when making video recordings of their own conversations.

3. Distillation of the components of the eight BCA sessions into four 1-hour BCPPA sessions (the duration agreed-upon by speech and language therapists as feasible ${ }^{11,12}$ )

Table 1. Learning objectives and timeline for development of the BCPPA training modules including the therapy program 


\begin{tabular}{|c|c|c|c|}
\hline $\begin{array}{l}\text { BCPPA } \\
\text { training } \\
\text { modules }\end{array}$ & $\begin{array}{l}\text { Learning objectives for speech and } \\
\text { language therapists accessing the module }\end{array}$ & $\begin{array}{l}\text { Co-produced module } \\
\text { components }\end{array}$ & $\begin{array}{l}\text { Development } \\
\text { timeline }\end{array}$ \\
\hline $\begin{array}{l}\text { Module 1: } \\
\text { What is } \\
\text { PPA? }\end{array}$ & $\begin{array}{l}\text { To explain what PPA is according to: } \\
\text { People with PPA and their relatives who } \\
\text { have worked on this module, } \\
\text { Speech and language therapists working in } \\
\text { the area } \\
\text { The research literature in this area }\end{array}$ & $\begin{array}{l}\text { Co- produced with steering } \\
\text { group. } \\
\text { References selected by steering } \\
\text { group. }\end{array}$ & $\begin{array}{l}\text { Prior to } \\
\text { launch of } \\
\text { online } \\
\text { BCPPA } \\
\text { program }\end{array}$ \\
\hline $\begin{array}{l}\text { Module 2: } \\
\text { What is } \\
\text { conversation } \\
\text { training? }\end{array}$ & $\begin{array}{l}\text { To explain what conversation training is to } \\
\text { clients, based on video recorded interviews } \\
\text { with: } \\
\text { Speech and language therapists working in } \\
\text { the area } \\
\text { People with PPA and their relatives who } \\
\text { have worked on this module. }\end{array}$ & $\begin{array}{l}\text { Co- produced with steering } \\
\text { group } \\
\text { Video clips planned, filmed and } \\
\text { selected by steering group }\end{array}$ & $\begin{array}{l}\text { Prior to } \\
\text { launch of } \\
\text { online } \\
\text { BCPPA } \\
\text { program }\end{array}$ \\
\hline $\begin{array}{l}\text { Module 3: } \\
\text { How to } \\
\text { make a } \\
\text { video }\end{array}$ & $\begin{array}{l}\text { - To have an appropriate tool available to } \\
\text { gain consent for the purpose of videoing of } \\
\text { a couple in conversation with one another } \\
\text { to be used in the conversation training } \\
\text { intervention, BCPPA. } \\
\text { - To be aware of the Mental Capacity Act } \\
\text { (2005) and how this will impact on consent. } \\
\text { - For speech and language therapists to be } \\
\text { supported to make and store videos, in line } \\
\text { with the data management guidance and } \\
\text { policies of their local organisation, of } \\
\text { conversation between a client and their } \\
\text { conversation partner for the purpose of the } \\
\text { BCPPA intervention. } \\
\text { - To be able to set up an optimal } \\
\text { environment for the purposes of making a } \\
\text { video for the BCPPA intervention }\end{array}$ & $\begin{array}{l}\text { Co-produced work with the } \\
\text { steering group included: a topic } \\
\text { sheet to support participants in } \\
\text { identifying what to discuss during } \\
\text { video recording, example consent } \\
\text { forms, video samples and } \\
\text { formatting of module. }\end{array}$ & $\begin{array}{l}\text { Prior to } \\
\text { Phase II } \\
\text { RCT } \\
\text { Feasibility } \\
\text { Pilot Study }\end{array}$ \\
\hline $\begin{array}{l}\text { Module 4: } \\
\text { What to } \\
\text { target in } \\
\text { therapy }\end{array}$ & $\begin{array}{l}\text { To understand the three stages of the goal } \\
\text { setting process: } \\
\text { 1) Identification of facilitators and barriers } \\
\text { from pre-therapy videos } \\
\text { 2) Selection of suitable video clips of } \\
\text { appropriate length and focus to show } \\
\text { clients, and } \\
\text { 3) Negotiation of goals with a person with } \\
\text { PPA and their conversation partner }\end{array}$ & $\begin{array}{l}\text { Co- produced work with people } \\
\text { with PPA included: video samples } \\
\text { and formatting of module. }\end{array}$ & $\begin{array}{l}\text { Prior to } \\
\text { Phase II } \\
\text { RCT } \\
\text { Feasibility } \\
\text { Pilot Study }\end{array}$ \\
\hline $\begin{array}{l}\text { Module 5: } \\
\text { BCPPA } \\
\text { therapy }\end{array}$ & $\begin{array}{l}\text { To deliver the four synchronous BCPPA } \\
\text { therapy sessions, supporting people with } \\
\text { PPA and their communication partners (as } \\
\text { a dyad) to: } \\
\text { - Understand concept of barriers and } \\
\text { facilitators in conversation and consider } \\
\text { thesis briefly in relation to their own } \\
\text { conversation } \\
\text { - Identify barriers and facilitators in their } \\
\text { own conversation } \\
\text { - Set goals for therapy based on this } \\
\text { discussion } \\
\text { - Practice conversation using the strategies } \\
\text { identified during goal setting }\end{array}$ & $\begin{array}{l}\text { Co- produced work with steering } \\
\text { group included: Therapy } \\
\text { handouts for sessions } 1 \text { and } 4 \text {, } \\
\text { therapy activities for session } 3 \text {, } \\
\text { video samples and formatting of } \\
\text { module. }\end{array}$ & $\begin{array}{l}\text { Prior to } \\
\text { Phase II } \\
\text { RCT } \\
\text { Feasibility } \\
\text { Pilot Study }\end{array}$ \\
\hline
\end{tabular}

Page 10/29 


\begin{tabular}{|c|c|c|c|}
\hline & $\begin{array}{l}\text { - Problem solve any issues that have arisen } \\
\text { in using identified strategies in } \\
\text { conversations outside of therapy sessions } \\
\text { - Consider planning for future changes in } \\
\text { communication }\end{array}$ & & \\
\hline $\begin{array}{l}\text { Module 6: } \\
\text { Measuring it }\end{array}$ & $\begin{array}{l}\text { - To consider what options are available for } \\
\text { measuring outcomes for BCPPA; } \\
\text { - To think about the pros and cons of } \\
\text { different outcome measures; } \\
\text { - To consider how to use outcome } \\
\text { measures in clinical practice. }\end{array}$ & $\begin{array}{l}\text { Co-produced with speech and } \\
\text { language therapists working with } \\
\text { people with PPA (local } \\
\text { collaborators who participated in } \\
\text { the Phase II RCT Feasibility } \\
\text { Study) }\end{array}$ & $\begin{array}{l}\text { Prior to } \\
\text { launch of } \\
\text { online } \\
\text { BCPPA } \\
\text { program }\end{array}$ \\
\hline $\begin{array}{l}\text { Module 7: } \\
\text { Useful } \\
\text { Resources }\end{array}$ & $\begin{array}{l}\text { - To learn about some activities people } \\
\text { with PPA enjoy; } \\
\text { - To find out about some useful websites } \\
\text { and resources; } \\
\text { - To have thought about what has been } \\
\text { useful in your therapy. }\end{array}$ & $\begin{array}{l}\text { Co-produced with steering group } \\
\text { Online resources selected by } \\
\text { steering group }\end{array}$ & $\begin{array}{l}\text { Prior to } \\
\text { launch of } \\
\text { online } \\
\text { BCPPA } \\
\text { program }\end{array}$ \\
\hline
\end{tabular}

NB: The language used for module titles and learning objectives reflects vocabulary selected by the steering group during co-production and was felt appropriate and accessible for the target audience (clinical speech and language therapists).

Table 2. Overview of content for the first draft of the BCPPA manual (Modules 3, 4 \& 5). 


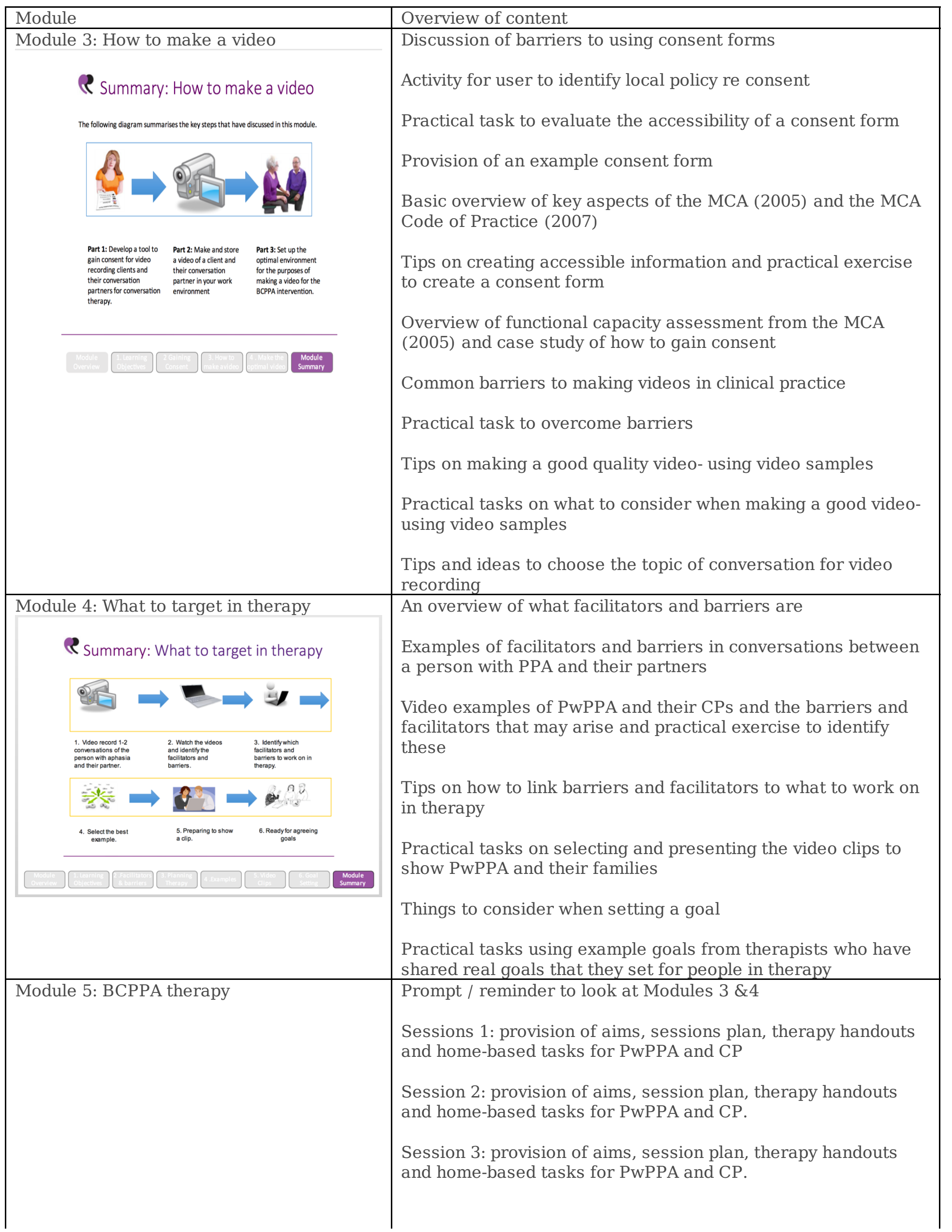

Page 12/29 
Summary of BCPPA therapy.

The following diagram summarises the four sessions in BCPPA.

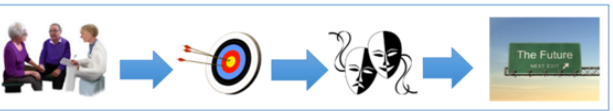

Session 1: What is Session 2: Goal Session 3: Practice Session 4: Problem

conversation? setting $\quad$ the strategies solving and planning

Introduce the View the dyads identified during the for future changes in

therapy and

videos and
Session 4: provision of aims, session plan, therapy handouts and home-based tasks for PwPPA and CP.

\section{First draft of BCPPA manual (Stage 3)}

Module 5: the BCPPA therapy, hosted the BCPPA manual comprising session plans, session handouts and home-based tasks for each of the four BCPPA intervention sessions. The session plans identified intervention components as either core or non-essential components that can be tailored to an individual's needs.

The draft manual was evaluated by the steering group to ensure information was presented in an accessible way. This included decisions on images and formatting.

The first draft of the manual was uploaded to a secure area on the UCLeXtend website and made available to speech and language therapists participating in the stage 4 consensus work via a bespoke URL. It was not publicly accessible.

\section{Consensus work (Nominal Group Technique) with speech and language therapists (Stage 4)}

Demographics and characteristics of speech and language therapist participants

Thirty-six speech and language therapists took part. Of these, 17 had completed the pre- NGT meeting survey, 22 had viewed the first draft of the BCPPA manual and training program prior to attending, and two had been able to use the BCPPA manual with a client with PPA. Table 3 presents speech and language therapist participant demographics and their familiarity with the BCPPA manual and training program. Following the meeting, 20 of the 36 participants completed the final NGT ranking task by email.

Table 3: Demographics of SLTs who participated in the NGT meeting and their familiarity with the BCPPA program 


\begin{tabular}{|l|l|}
\hline & $\begin{array}{l}\text { SLT } \\
\text { participants } \\
(\mathrm{n}=36)\end{array}$ \\
\hline Gender (m:f) & $2: 34$ \\
\hline $\begin{array}{l}\text { Years practicing as an SLT (mean and range) } \\
\text { (mean and range) }\end{array}$ & $12.5(0-21)$ \\
\hline $\begin{array}{l}\text { BCPPA modules viewed online prior to meeting: } \\
\text { None but knows of BCA }\end{array}$ & $9(0-20)$ \\
None & 1 \\
Module 3 How to make a video Module & 11 \\
4 What to target in therapy & 22 \\
Module 5 BCPPA therapy & 21 \\
& 22 \\
\hline
\end{tabular}

m: male, f: female, SLT: speech and language therapist, PPA: primary progressive aphasia, BCA: Better Conversations with Aphasia program, BCPPA: Better Conversations with PPA program.

\section{Pre-NGT meeting survey}

When asked what surprised them when they first accessed the online BCPPA program five of 17 respondents $(29 \%)$ commented on there being a lot of detail. Five respondents $(29 \%)$ described the program as clear, easy to use and accessible; one person highlighted the comprehensive and detailed step by step guidance. A further four respondents (24\%) stated that they were unsurprised by the BCPPA program, given their familiarity with the BCA program on which BCPPA is based. Respondents provided feedback on the BCPPA program including the most useful aspects $(17,100 \%$, respondents), formatting $(16,94 \%$, respondents), additions or changes $(14,82 \%$, respondents) and the least useful aspects of the program (10,60\%, of respondents). Five themes arose from these data: 1 . General usefulness; 2 . Specific 'helpful' tasks or sections; 3. Access issues, 'I had trouble with'; 4. 'Could you add'; 5. 'Not a fan'. These 
themes are illustrated with quotes in Figure 2. Notably, access issues were generally related to glitches in the program, though some local NHS browser systems posed restrictions.

Nominal Group Technique

After two iterations of consensus work with speech and language therapists, focused on the question "What components of the BCPPA therapy sessions are important for people with PPA and their conversation partners?", eight components were identified, and ranked in order of importance, see Table 4.

Table 4: Final eight ranked components identified as important for the BCPPA program, from two stage NGT consensus work

\begin{tabular}{|l|l|}
\hline 1 & $\begin{array}{l}\text { Use of video feedback to identify facilitators versus barriers in conversation when } \\
\text { focusing on people's strengths as well as areas of potential breakdown }\end{array}$ \\
\hline 2 & $\begin{array}{l}\text { Tailored and person centred: } \\
\text { - goals, } \\
\text { - conversational topics, } \\
\text { - strategies } \\
\text { - practice opportunities }\end{array}$ \\
\hline 3 & Emphasising a focus on getting message across rather than a perfect interaction \\
\hline 4 & $\begin{array}{l}\text { Focusing individual attention on non-verbal communication strategies such as body } \\
\text { language, gesture, facial expression and other methods of total communication. }\end{array}$ \\
\hline 5 & Recognising and building on current communication strengths. \\
\hline 6 & Working with both the person with PPA and the CP together. \\
\hline 7 & Providing opportunities to practice strategies and get feedback from the SLT. \\
\hline 8 & Providing an opportunity to discuss their communication difficulties \\
\hline
\end{tabular}

\section{Focus groups with people with PPA and their families (Stage 5)}

Demographics of participants

Thirteen participants, six people with PPA and seven family members, responded to the advertisement. All were eligible and agreed to participate but one couple withdrew the day before the focus group due to a conflicting commitment. The remaining 11 participants attended two focus groups (NB: these were mixed groups, whereby people with PPA and their CPs attended together, alongside some CPs and people with PPA who attended independently, group 1: seven participants; group 2: four participants). Participants 
with PPA represented all three variants, and atypical mixed variants. Demographic information is outlined in Table 5.

Table 5: Demographic information for focus group participants

\begin{tabular}{|c|c|c|c|c|}
\hline & $\begin{array}{l}\text { Person with PPA (PwPPA) and } \\
\text { communication partner (CP) }\end{array}$ & $\begin{array}{l}\text { PPA } \\
\text { variant }\end{array}$ & $\begin{array}{l}\text { Time since } \\
\text { symptom onset }\end{array}$ & $\begin{array}{l}\text { Time since } \\
\text { diagnosis }\end{array}$ \\
\hline Focus & PwPPA (m) + CP (f) & $\operatorname{lvPPA}$ & 4 years, & 2 years \\
\hline \multirow[t]{3}{*}{ Group 1: } & PwPPA (f) + CP (m) & Mixed & 3 years & 2 years \\
\hline & $\mathrm{CP}(\mathrm{f})$ & (Mixed) & (9 years) & (4 years) \\
\hline & PwPPA (f) + CP (m) & nfvPPA & 5 years & 4 years \\
\hline Focus & PwPPA (m) & $\operatorname{lvPPA}$ & 4 years, & 1 year \\
\hline \multirow[t]{2}{*}{ Group 2: } & PwPPA (f) + CP (m) & svPPA & 5 years & 4 years \\
\hline & $\mathrm{CP}(\mathrm{m})$ & (Mixed) & (8 years) & (5 years) \\
\hline
\end{tabular}

PwPPA: person with primary progressive aphasia, CP: communication partner, lvPPA: logopenic variant primary progressive aphasia, svPPA: semantic variant primary progressive aphasia, nfvPPA: non-fluent agrammatic variant primary progressive aphasia

Themes arising from the focus groups

Three overarching themes emerged: 1) Timing of intervention, 2) speech and language therapists' understanding of types of dementia, and 3 ) Knowing what helps. Theme 3 encompassed five further subthemes: 'No one size fits all', 'I've discovered that', 'who's targeted', 'therapy approaches' and 'toolkit'. All themes and subthemes are presented in relation to illustrative units of data in Figure 3.

\section{Refinement of BCPPA manual (Stage 6)}

Refinements that arose from stages 4 and 5 of intervention development were decided on in conjunction with the steering group and are presented in Table 6 . The refined BCPPA program was consequently made available to participating local speech and language therapist collaborators on UCLeXtend as part of their training in preparation for delivering the intervention during the randomised controlled pilotfeasibility study. The final intervention is described in detail, using the template for Intervention Description and Replication (TiDIER), in the authors PhD thesis which this paper is based on ${ }^{51}$, and a published protocol for study which remains currently underway ${ }^{52}$. Further to this, the project steering 
group made plans to continue working to co-produce the remaining four modules, in anticipation of a future launch of the BCPPA program. This paper is based on work from the authors PhD thesis.

Table 6: Refinements for BCPPA manual and intervention 


\begin{tabular}{|c|c|}
\hline Decisions made & Examples of refinements made \\
\hline $\begin{array}{l}\text { Provide more } \\
\text { options on } \\
\text { strategies and } \\
\text { practice } \\
\text { activities in the } \\
\text { intervention } \\
\text { materials. }\end{array}$ & $\begin{array}{l}\text { Addition of Home based task } 2 \text { : Strategies to help } \\
\text { turntaking and expansion of session plan } 3 \text { to } \\
\text { include a list of } 11 \text { optional additional strategy } \\
\text { practice ideas based on ideas collated from SLTs, } \\
\text { people with PPA and their families and a review } \\
\text { of manuals for stroke aphasia CPT manuals. }\end{array}$ \\
\hline $\begin{array}{l}\text { Provide more } \\
\text { information on } \\
\text { resources and } \\
\text { other services. }\end{array}$ & $\begin{array}{l}\text { Expansion of session plan } 4 \text { to include a list of } \\
\text { resources and other services for SLTs making } \\
\text { recommendations for the future. }\end{array}$ \\
\hline $\begin{array}{l}\text { Develop video } \\
\text { examples of the } \\
\text { intervention } \\
\text { being } \\
\text { delivered. }\end{array}$ & $\begin{array}{l}\text { Addition of video recordings of conversation } \\
\text { breakdown and intervention being delivered } \\
\text { inserted to Module 5: The BCPPA therapy. These } \\
\text { included: } \\
\text { Session 1: } \\
\text { Video examples of Keith and Rose watching } \\
\text { videos of themselves and the SLT facilitating } \\
\text { them to identify barriers and facilitators. } \\
\text { Session 2: } \\
\text { Video examples of Keith and Rose goal setting } \\
\text { with the SLT. } \\
\text { Session 4: } \\
\text { Video example of Keith and the SLT discussing a } \\
\text { difficult subject around future planning. }\end{array}$ \\
\hline $\begin{array}{l}\text { Include more } \\
\text { testimonies from } \\
\text { people with PPA } \\
\text { in Module 1: } \\
\text { What is PPA and } \\
\text { Module 2: What } \\
\text { is } \\
\text { communication } \\
\text { partner } \\
\text { training? }\end{array}$ & $\begin{array}{l}\text { Use of quotes to illustrate experience of } \\
\text { communication facilitators and barriers in Module } \\
\text { 4: What to target in therapy. }\end{array}$ \\
\hline $\begin{array}{l}\text { Provide more } \\
\text { information on } \\
\text { how PPA } \\
\text { impacts on daily } \\
\text { communication. }\end{array}$ & $\begin{array}{l}\text { Refinement of Session } 1 \text {. Handout } 1 \text {. How does } \\
\text { conversation work? And addition of Session } 1 . \\
\text { Handout } 2 \text {. What can go wrong in conversations? } \\
\text { in co- production with project steering group. }\end{array}$ \\
\hline Provide a & Addition of summary handout for session 4: \\
\hline
\end{tabular}


summary sheet

including

suggestions for

future changes

on one handout

at the end of the

intervention.

$\mathrm{BCPPA}=$ Better Conversations with Primary Progressive Aphasia, SLT $=$ speech and language therapist, PPA=primary progressive aphasia

\section{Discussion}

The BCPPA manual and training program were developed using the framework described in the MRC guidelines for development of complex interventions ${ }^{27}$. The intervention content is underpinned by the bio-psychosocial model of dementia, applied CA, behaviour change theory, and self-management and self-efficacy literature. Consultation and co-production work with a project steering group made up of people with PPA and their family members provided the first draft of the BCPPA manual and training program. Consensus work using a Nominal Group Technique with practicing speech and language therapists, and focus groups with people with PPA and their families, identified further refinements. These included additions to the manual, and modifications to improve access to and use of the materials within the modules.

Speech and language therapists report seeing people with PPA in their clinics who feel incompetent in conversations, whilst their CPs feel helpless to support them in these situations ${ }^{53}$. Addressing this by exploring meaningful strategies to maintain conversation via CPT that involves both a person with PPA and their $\mathrm{CP}$ has been recommended by expert speech and language therapists ${ }^{26}$. Currently, speech and language therapists delivering CPT to people with PPA and their CPs report using tools designed for people with stroke aphasia because there are no PPA-specific materials ${ }^{11,12}$. The BCPPA manual and training program address this gap in the speech and language therapists' "toolkit" (described as such by participants in the focus groups) of interventions for PPA, and provides an evidence based, manualised training resource designed by and for people with PPA and their CPs.

\section{Strengths And Limitations}

Drawing on the best available evidence and appropriate theory to develop the BCPPA manual, in accordance with MRC guidance ${ }^{27}$, should increase the likelihood that components of the intervention result in behaviour change. Extensive use of theory has been associated with larger effect sizes in a review of online behaviour change interventions ${ }^{54}$. This work has involved new research with those targeted by the intervention as well as those delivering it.

There are, however, some methodological limitations. NGT does not allow for anonymisation in the way that other consensus methods such as Delphi do, and can thus bias the responses of participants. 
Though, the NGT did provide a method of involving large participant numbers and incorporating mathematical voting techniques to aggregate group judgements equally ${ }^{32}$. Making the intervention manual available for scrutiny of its practicality for clinical practice in this way has allowed for prioritisation of key components in anticipation of the phase II NHS based randomised controlled pilotfeasibility study. Notably, only two males were recruited to the NGT, though this is generally representative of the current SLT community ${ }^{55}$. Despite being a useful method for eliciting participant's genuine and honest opinions, a focus group can be a challenging communication environment ${ }^{56}$. The role of the speech and language therapist facilitator and the student speech and language therapist co-facilitators was to mitigate this by enabling participants to contribute to discussion. The option to attend with CPs to support communication was also provided, but instead participants prioritised the convenience of meeting dates and times. Given the steering group was established a number of years prior to the recently published practice standards for $\mathrm{PI}^{57}$ it is likely that the methods employed may have limited the effectiveness of the co-produced work. Some have criticised the steering group model for consulting with only a small number of individuals. There were only three couples with PPA in this group and that may have limited its value. PPA is, however, a relatively rare condition and people were approached to reflect the known diversity within the condition. Additionally, new members were sought when others withdrew due to disease progression, and the author sought to gather perspectives of other people and their families through individual telephone contact. Despite approaching professionals from other disciplines, including medicine and social work, interested individuals were not able to attend steering group meetings. The author was able to consult with the research team, including neurology colleagues, to gather feedback and ideas.

A manualised approach enables standardised delivery of the intervention for a future trial. Given that speech and language therapists in clinical practice may have limited experience of working with people with PPA ${ }^{10,11}$, this helps to maximise ease and fidelity of delivery for future implementation. However, a manualised intervention may limit the potential to tailor an intervention to individual clients, for example by deciding not to use video recording or by delivering the intervention to a person accompanied by two CPs. Person-centred components have been identified as important for functional communication interventions for people with PPA, and have been highlighted as important for behaviour change $\mathrm{e}^{46,49}$. The development of this intervention took behaviour change theory into account and embedded the core processes and mechanisms that had been identified in previous CPT research as essential components. These were clearly signposted in the manual and distinguished from non-essential components that were amendable to tailoring. Furthermore, expecting four 1-hour therapy sessions to result in a change may seem ambitious. However, the decision on dosage was made based on the average number of sessions that speech and language therapists reported having available to deliver functional communication interventions for PPA ${ }^{11}$. Developing an intervention that meets this requirement increases the chance of implementation.

\section{Conclusions}


The six-stage process of development included a review of existing literature, and consultation and coproduction with the project steering group to develop an initial draft. Consensus work undertaken with speech and language therapists and focus groups with people with PPA and their families identified further refinements. The BCPPA manual was refined in preparation for a phase II NHS based randomised controlled pilot-feasibility study which is currently underway 52 .

\section{Abbreviations}

PPA: Primary Progressive Aphasia; svPPA: semantic variant PPA; IvPPA: Logopenic variant PPA; nfvPPA: non-fluent variant PPA; SLT: Speech and Language Therapy; CP: Communication Partner; CPT: Communication Partner Training; BCPPA: Better Conversations for Primary Progressive Aphasia; PI: Public Involvement; NGT: Nominal Group Technique; NHS: National Health Service; MRC: Medical Research Council; CA: Conversation Analysis.

\section{Declarations}

\section{Ethics approval and consent to participant}

All work undertaken in this study was was conducted in accordance with

the Declaration of Helsinki.

Consultation and co-production work (Stage 2): Ethical approval is not required when involving individuals in the planning or design of research, for example when they are members of a research steering or advisory group (Health Research Authority, 2019). In order to equalize participation and power issues specific strategies were used in and outside of the steering group meetings. All communication, written and spoken, was made accessible to ensure no individuals were disadvantaged. All steering group members were required to use the same methods to contribute (raising a card to indicate they had a question or comment). People with communication difficulties were invited to contribute before others, and the author made contact with individuals with communication difficulties prior to the meeting to gather initial thoughts, to support facilitation during group discussions.

Consensus work with speech and language therapists (Stage 4): The UCL Research Ethics Committee confirmed the NGT consensus work (Stage 4) with speech and language therapist participants to be service evaluation. Participants were informed that all responses would be anonymous and at the start of the event they provided written informed consent to participate.

Focus groups with people with PPA and their families (Stage 5): Camden and Kings Cross Research Ethics Committee (IRAS ID: 202353, Rec Ref: 17/LO/0357) approved the focus group study. Informed consent was obtained by A.V. following the current guidance from the Mental Capacity Act (Department of Health, 2005) and Royal College of Speech and Language Therapy (RCSLT), regarding gaining consent 
from people with communication difficulties. A caregiver (a friend or relative) was asked to witness the informed consent process whenever possible.

Participant information sheets, consultee information sheets, consent forms and consultee declaration forms were designed to be accessible to support the process of gaining informed consent. They were designed using a resource for researchers in communication disability "Engaging people who have aphasia" (Pearl, 2014) and modified with advice from the project steering group. Transcriptions of focus group data were anonymised via the allocation to each participant of a unique research number, used at all times. All names, places and personal information mentioned in the discussions were pseudonymised.

The addition of video recordings demonstrating delivery of the intervention had ethical implications, requiring a minor amendment to HRA ethical approval. Having received this approval, a separate dyad were recruited through an email advert to members of the PPA branch of the UCL Rare Dementia Support Group. During the consent process it was made clear to the dyad there would be a risk that their faces and voices may be recognized from their video recordings. Information was provided regarding the course registration process and expected registrants, such as health professionals and people with PPA and their families. After consenting to participate, the dyad made four pre-intervention video recordings of their conversations, and received BCPPA therapy from the author, an experienced speech and language therapist. All four therapy sessions were video recorded. The author then identified a selection of short video clips that illustrated key components of the intervention such as the process of supporting dyads to identify barriers and facilitators in their conversation sample, goal setting, and discussion about planning for the future. The dyad viewed these clips prior to giving final consent for their inclusion in Module 5.

\section{Consent for Publication}

Not applicable

\section{Availability of data and materials}

Not applicable

\section{Competing Interests}

The authors declare that they have no competing interests

\section{Funding}

AV was funded by a National Institute for Health Research Doctoral Research Fellowship 2015-08-182 JDW receives grant support from the Alzheimer's Society, Alzheimer's Research UK and the NIHR UCLH Biomedical Research Centre

This paper presents independent research funded by the National Institute for Health Research (NIHR). The views expressed are those of the authors and not necessarily those of the NHS, the NIHR or the 
Department of Health.

Components of work described in this paper were presented at the Academy of Aphasia 57th Annual Meeting, Macau, Macau, 27 Oct - 29 Oct, 2019 as a conference talk with interim findings. The abstract was published in "Aphasia in neurodegenerative conditions." in Frontiers in Human Neurosciences: Hyperlink with DOI: https://www.frontiersin.org/10.3389\%2Fconf.fnhum.2019.01.00106/event_abstract

\section{Authors' contributions}

This paper is based on work from the first authors PhD thesis. AV conceived and designed the study, collected, analysed and interpreted data with supervision and support from SB, AS, KS and JW. AV drafted the article with guidance from SB, AS, KS and JW, all authors critically reviewed the article and are accountable for all aspects of the work.

\section{Acknowledgments}

Dr Abi Roper, Dr Claudia Bruns, Dr Gwen Breklemans and Anna Sowerbutts all contributed to the development of the electronic version of the BCPPA modules in preparation for the upload to the UCLeXtend website. Sara Bunker and Claire Tryfonidis were the SLT students, now qualified therapists, who aided in the facilitation of the focus groups with people with PPA and their families. Nicola Sirman and Firle Beckley acted as SLT researchers working on the thematic analysis of the focus group data.

\section{References}

1. World Health Organisation. Dementia factsheet. 2019. https://www.who.int/news-room/factsheets/detail/dementia. Accessed June 2020.

2. Marshall CR, Hardy CJ, Volkmer A, Russell LL, Bond RL, Fletcher PD, Clark CN, Mummery CJ, Schott JM, Rossor MN, Fox NC. Primary progressive aphasia: a clinical approach. Journal of Neurology. 2018;265(6):1474-90.

https://doi.org/10.1007/s00415-018-8762-6

3. Gorno-Tempini ML, Hillis AE, Weintraub S, Kertesz A, Mendez M, Cappa SF, Ogar JM, Rohrer JD, Black S, Boeve BF, Manes F. Classification of primary progressive aphasia and its variants. Neurology. 2011 Mar 15;76(11):1006-14. https://doi.org/10.1212/WNL.0b013e31821103e6

4. Gould Mike's lifeline. RCSLT Bulletin, 2015;760:17. Retrieved from https://www.rcslt.org/docs/bulletin/2015/aug_2015

5. Ruggero L, Nickels L, Croot K. Quality of life in primary progressive aphasia: What do we know and what can we do next?. Aphasiology. 2019;33(5):498-519.

https://doi.org/10.1080/02687038.2019.1568135 
6. Pozzebon M, Douglas J, Ames D. Spousal recollections of early signs of primary progressive aphasia. International journal of language \& communication disorders. 2018;53(2):282-93.

https://doi.org/10.1111/1460-6984.12347

7. Jokel R, Graham NL, Rochon E, Leonard C. Word retrieval therapies in primary progressive aphasia. Aphasiology. 2014;28(8-9):1038-68.

https://doi.org/10.1080/02687038.2014.899306

8. Carthery-Goulart MT, Silveira AD, Machado TH, Mansur LL, Parente MA, Senaha ML, Brucki SM, Nitrini R. Nonpharmacological interventions for cognitive impairments following primary progressive aphasia: a systematic review of the literature. Dementia \& Neuropsychologia. 2013;7(1):122-31. https://doi.org/10.1590/S1980-57642013DN70100018

9. Croot K. Progressive language impairments: Definitions, diagnoses, and prognoses. Aphasiology. 2009;23(2):302-26. https://doi.org/10.1080/02687030801942981

10. Volkmer A, Spector A, Meitanis V, Warren JD, Beeke S. Effects of functional communication interventions for people with primary progressive aphasia and their caregivers: a systematic review. Aging \& mental health. 2020;24(9):1381-93.

Doi:10.1080/13607863.2019.1617246

11. Volkmer A, Spector A, Warren JD, Beeke S. Speech and language therapy for primary progressive aphasia: Referral patterns and barriers to service provision across the UK. Dementia. 2020;19(5):1349-63. Doi: 10.1177/1471301218797240

12. Volkmer A, Spector A, Warren JD, Beeke S. Speech and language therapy for primary progressive aphasia across the UK: A survey of current practice. International journal of language \& communication disorders. 2019;54(6):914-26. Doi:10.1111/1460-6984.12495 》

13. Kindell J, Keady J, Sage K, Wilkinson R. Everyday conversation in dementia: a review of the literature to inform research and practice. International journal of language \& communication disorders. 2017;52(4):392-406. https://doi.org/10.1111/1460-6984.12298

14. Perkins $L$, Whitworth $A$, Lesser R. Conversing in dementia: A conversation analytic approach. Journal of Neurolinguistics. 1998;11(1-2):33-53. https://doi.org/10.1016/S0911-6044(98)00004-9

15. Wilkinson R. Conversation and aphasia: Advances in analysis and intervention. 2015;29(3):257-268. https://doi.org/10.1080/02687038.2014.974138

16. Simmons-Mackie N, Savage MC, Worrall L. Conversation therapy for aphasia: a qualitative review of the literature. International Journal of Language \& Communication Disorders. 2014;49(5):511-26. https://doi.org/10.1111/1460-6984.12097

17. Eggenberger $\mathrm{E}$, Heimerl $\mathrm{K}$, Bennett MI. Communication skills training in dementia care: a systematic review of effectiveness, training content, and didactic methods in different care settings. Database of 
Abstracts of Reviews of Effects (DARE): Quality-assessed Reviews [Internet]. 2013. https://doi.org/10.1017/S1041610212001664

18. Kagan A. Supported conversation for adults with aphasia: Methods and resources for training conversation partners. Aphasiology. 1998;12(9):816-30.

https://doi.org/10.1080/02687039808249575

19. Beeke S, Johnson F, Beckley F, Heilemann C, Edwards S, Maxim J, Best W. Enabling better conversations between a man with aphasia and his conversation partner: Incorporating writing into turn taking. Research on Language and Social Interaction. 2014;47(3):292-305. https://doi.org/10.1080/08351813.2014.925667

20. Best W, Maxim J, Heilemann C, Beckley F, Johnson F, Edwards SI, Howard D, Beeke S. Conversation therapy with people with aphasia and conversation partners using video feedback: a group and case series investigation of changes in interaction. Frontiers in human neuroscience. 2016;10:562. https://doi.org/10.3389/fnhum.2016.00562

21. Murray LL. Longitudinal treatment of primary progressive aphasia: A case study. Aphasiology. 1998;12(7-8):651-72. https://doi.org/10.1080/02687039808249564

22. Wong SB, Anand R, Chapman SB, Rackley A, Zientz J. When nouns and verbs degrade: Facilitating communication in semantic dementia. Aphasiology. 2009;23(2):286-

301.https://doi.org/10.1080/02687030801943112

23. Taylor-Rubin C, Croot K, Power E, Savage SA, Hodges JR, Togher L. Communication behaviors associated with successful conversation in semantic variant primary progressive aphasia. International Psychogeriatrics, 2017;10:619-1632. https://doi.org/10.1017/S1041610217000813

24. Jokel R, Meltzer J. Group intervention for individuals with primary progressive aphasia and their spouses: Who comes first?. Journal of communication disorders. 2017;66:5164.https://doi.org/10.1016/j.jcomdis.2017.04.002

25. Douglas JT. Adaptation to early-stage nonfluent/agrammatic variant primary progressive aphasia: A first-person account. American Journal of Alzheimer's Disease \& Other Dementias®. 2014;29(4):28992. https://doi.org/10.1177\%2F1533317514523669

26. Kindell J, Sage K, Cruice M. Supporting communication in semantic dementia: clinical consensus from expert practitioners. Quality in ageing and older adults. 2015;3:153-164. https://doi.org/10.1108/QAOA-08-2014-0016

27. Craig P, Dieppe P, Macintyre S, Michie S, Nazareth I, Petticrew M. Developing and evaluating complex interventions: the new Medical Research Council guidance. Bmj. 2008;29;337. https://doi.org/10.1136/bmj.a1937

28. Duncan E, O'Cathain A, Rousseau N, Croot L, Sworn K, Turner KM, Yardley L, Hoddinott P. Guidance for reporting intervention development studies in health research (GUIDED): an evidence-based consensus study. BMJ open. 2020;10(4):e033516. http://dx.doi.org/10.1136/bmjopen-2019-033516

29. Barrett J, Kirk S. Running focus groups with elderly and disabled elderly participants. Applied ergonomics. 2000;31(6):621-9. https://doi.org/10.1016/S0003-6870(00)00031-4 
30. Volkmer A, Beeke S. How to help couples have better conversations. Journal of Dementia Care. 2015;23(5):22-4.

31. Beckley F, Best W, Johnson F, Edwards S, Maxim J, Beeke S. Conversation therapy for agrammatism: Exploring the therapeutic process of engagement and learning by a person with aphasia. International journal of language \& communication disorders. 2013;48(2):220-39. https://doi.org/10.1111/j.1460-6984.2012.00204.x

32. Delbecq A L, Van de Ven A H, Gustafson D H. Group techniques for program planning : a guide to nominal group and Delphi processes (S. F. and Company., Ed.). Glenview:Ilinois; 1975.

33. McLellan E, MacQueen KM, Neidig JL. Beyond the qualitative interview: Data preparation and transcription. Field methods. 2003 Feb;15(1):63-84. https://doi.org/10.1177/1525822X02239573

34. Braun V, Clarke V. Using thematic analysis in psychology. Qualitative research in psychology. 2006 Jan 1;3(2):77-101. https://doi.org/10.1191/1478088706qp063oa

35. Braun V, Clarke V. One size fits all? What counts as quality practice in (reflexive) thematic analysis?. Qualitative research in psychology. 2020 Aug 14:1-25. https://doi.org/10.1080/14780887.2020.1769238

36. Spector A, Orrell M. Using a biopsychosocial model of dementia as a tool to guide clinical practice. International Psychogeriatrics. 2010 Sep 1;22(6):957. https://doi.org/10.1017/S1041610210000840

37. Kindell J, Keady J, Sage K, Wilkinson R. Everyday conversation in dementia: a review of the literature to inform research and practice. International journal of language \& communication disorders. 2017 Jul;52(4):392-406. https://doi.org/10.1111/1460-6984.12298

38. Kindell J, Sage K, Keady J, Wilkinson R. Adapting to conversation with semantic dementia: using enactment as a compensatory strategy in everyday social interaction. International Journal of Language \& Communication Disorders. 2013 Sep;48(5):497-507.

https://doi.org/10.1111/1460- 6984.12023

39. Sidnell J, Stivers T, editors. The handbook of conversation analysis. John Wiley \& Sons; 2012 Aug 3. https://doi.org/10.1002/9781118325001

40. Wilkinson R. Intervening with conversation analysis in speech and language therapy: Improving aphasic conversation. Research on Language and Social Interaction. 2014 Jul 3;47(3):219-38. https://doi.org/10.1080/08351813.2014.925659

41. Wilkinson R. Intervening with conversation analysis in speech and language therapy: Improving aphasic conversation. Research on Language and Social Interaction. 2014 Jul 3;47(3):219-38. https://doi.org/10.1080/08351813.2014.925659

42. Lock S, Wilkinson R, Bryan K, Maxim J, Edmundson A, Bruce C, Moir D. Supporting partners of people with aphasia in relationships and conversation (SPPARC). International Journal of Language \& Communication Disorders. 2001 Jan 1;36(sup1):25-30. DOI:3109/13682820109177853

43. Beeke S, Sirman N, Beckley F, Maxim J, Edwards S, Swinburn K, Best W. Better Conversations with Aphasia: an e-learning resource. 2013 https://extend.ucl.ac.uk/ Access June 2020 
44. Cruice M, Blom Johansson M, Isaksen J, Horton S. Reporting interventions in communication partner training: A critical review and narrative synthesis of the literature. Aphasiology. 2018 Oct 3;32(10):1135-66. https://doi.org/10.1080/02687038.2018.1482406

45. Beckley F, Best W, Johnson F, Edwards S, Maxim J, Beeke S. Conversation therapy for agrammatism: Exploring the therapeutic process of engagement and learning by a person with aphasia. International journal of language \& communication disorders. 2013 Mar;48(2):22039.https://doi.org/10.1111/j.1460-6984.2012.00204.x

46. Michie S, Van Stralen MM, West R. The behaviour change wheel: a new method for characterising and designing behaviour change interventions. Implementation science. 2011 Dec;6(1):1-2. https://doi.org/10.1186/1748-5908-6-42

47. Johnson FM, Best W, Beckley FC, Maxim J, Beeke S. Identifying mechanisms of change in a conversation therapy for aphasia using behaviour change theory and qualitative methods. International journal of language \& communication disorders. 2017 May;52(3):374-87. https://doi.org/10.1111/1460-6984.12279

48. Johnson F. What works in conversation therapy for aphasia, and how? Searching for mechanisms of change and active ingredients using tools and theory from behaviour change research. Unpublished PhD thesis: University College London. 2015 https://discovery.ucl.ac.uk/id/eprint/1472090/1/Johnson_Oct 2015 SUBMISSION Fiona Johnson Phd THESIS.pdf Accessed June 2020.

49. Turner A, Anderson JK, Wallace LM, Bourne C. An evaluation of a self-management program for patients with long-term conditions. Patient education and counseling. 2015 Feb 1;98(2):213-9. https://doi.org/10.1016/j.pec.2014.08.022

50. Yorkston K, Baylor C, Britton D. Incorporating the principles of self-management into treatment of dysarthria associated with Parkinson's disease. InSeminars in speech and language $2017 \mathrm{Jul}$ (Vol. 38, No. 3, p. 210). NIH Public Access. https://doi.org/10.1055/s-0037-1602840

51. Volkmer A.Better Conversations with Primary Progressive Aphasia (BCPPA): Developing and piloting a communication partner training intervention for people with primary progressive aphasia and their significant others. Unpublished PhD thesis: University College London. 2020. https://discovery.ucl.ac.uk/id/eprint/10100280/ Accessed June 2020.

52. Volkmer A, Spector A, Warren JD, Beeke S. The 'Better Conversations with Primary Progressive Aphasia (BCPPA)'program for people with PPA (Primary Progressive Aphasia): protocol for a randomised controlled pilot study. Pilot and feasibility studies. 2018 Dec;4(1):1-0. https://doi.org/10.1186/s40814-018-0349-6

53. Taylor C, Croot K, Power E, Savage SA, Hodges JR, Togher L. Trouble and repair during conversations of people with primary progressive aphasia. Aphasiology. 2014 Sep 2;28(8-9):1069-91. https://doi.org/10.1080/02687038.2014.930411

54. Webb T, Joseph J, Yardley L, Michie S. Using the internet to promote health behavior change: a systematic review and meta-analysis of the impact of theoretical basis, use of behavior change 
techniques, and mode of delivery on efficacy. Journal of medical Internet research. 2010;12(1):e4. https://doi.org/10.2196/jmir.1376

55. Litosseliti L, Leadbeater C. Speech and language therapy/pathology: perspectives on a gendered profession. International Journal of Language \& Communication Disorders. 2013 Jan;48(1):90-101. https://doi.org/10.1111/j.1460-6984.2012.00188.x

56. Wilkinson S. Focus groups in health research: Exploring the meanings of health and illness. Journal of Health Psychology. 1998 Jul;3(3):329-48. https://doi.org/10.1177/135910539800300304

57. Staniszewska S, Denegri S, Matthews R, Minogue V. Reviewing progress in public involvement in NIHR research: developing and implementing a new vision for the future. BMJ open. 2018 Jul 1;8(7):e017124. https://doi.org/10.1136/bmjopen-2017-017124

\section{Figures}

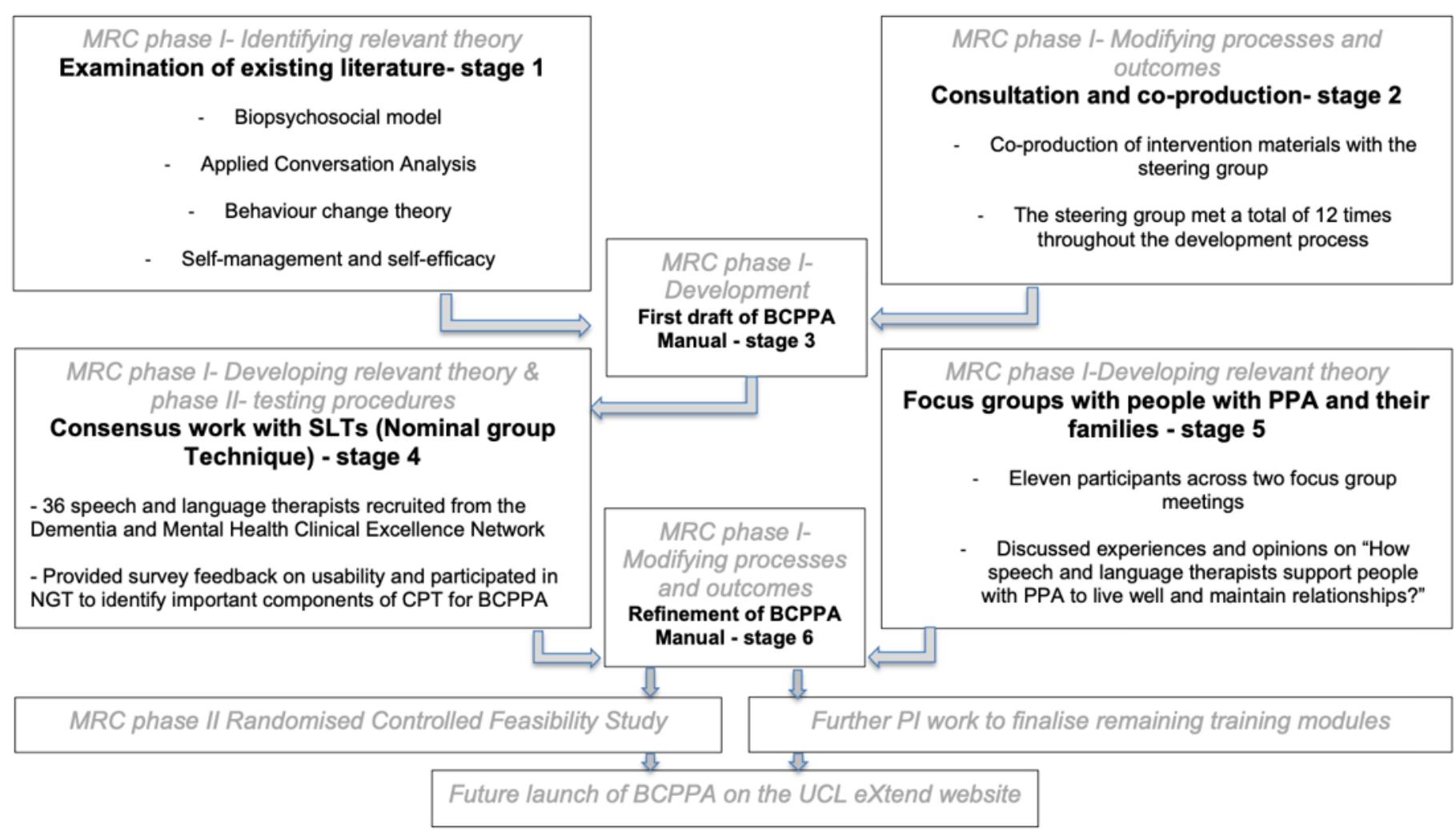

\section{Figure 1}

The six stages in the development BCPPA intervention and manual drafting, mapped on to the MRC framework for development of complex interventions. 
Theme 1:

General usefulness

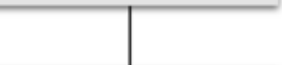

Respondents made positive comments about the general usefulness of

the modules and intervention

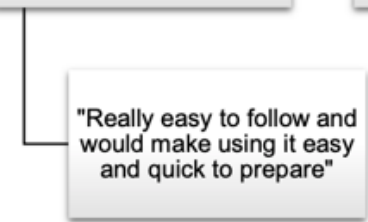

Theme 2:

Speicifc 'helpful' tasks or sections

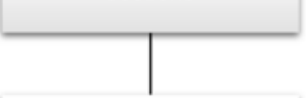

Respondents selected specific examples or particular elements they found useful

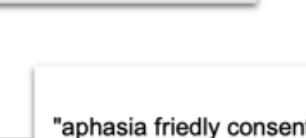

"aphasia friedly consent
form in really useful"

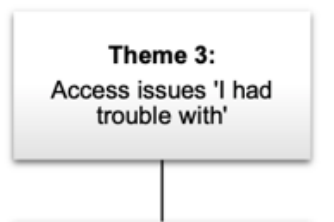

Respondents identified parts of the program they had difficulties using

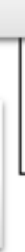

Theme 4:

'Could you add'

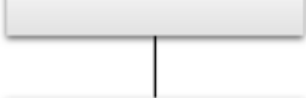

Respondents made suggestions for things to add or change
Theme 5:

'Not a fan'

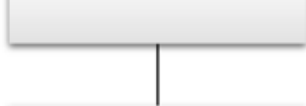

Respondents described things they did not find useful

\section{Figure 2}

Themes identified from survey responses in Stage 4 consensus work.

Theme 1:

Timing of Intervention

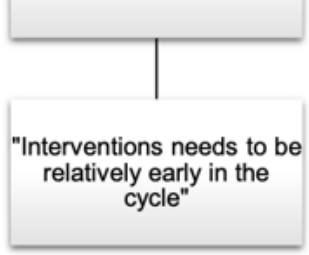

Theme 2:

SLT's understanding of types of dementia

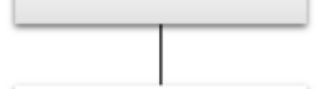

"I don't know whether this SLT really understood what semantic dmentia was"
Theme 3

Knowing what helps

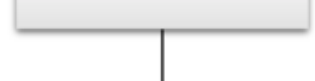

"It's really difficult to think about stuff by yourself. So if you could have a clear, sort of, flow chart, of things, strategies you could try, that you could pin on the fridge, an you can go back to. As a carer, I think, that would be enormously helpful."

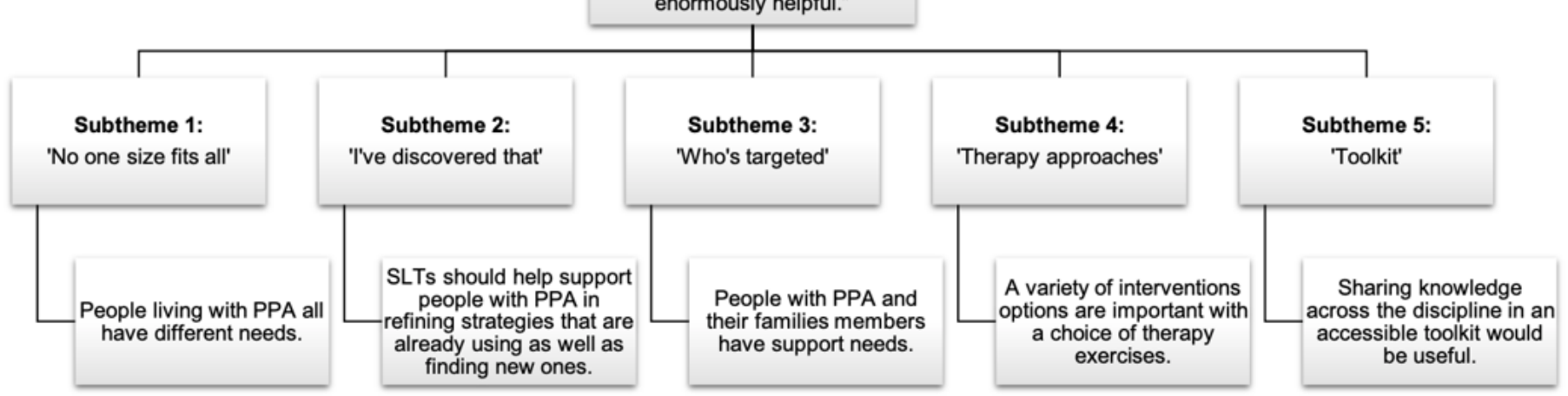

\section{Figure 3}

Themes and subthemes arising from focus groups with people with PPA and their CPs

\section{Supplementary Files}

This is a list of supplementary files associated with this preprint. Click to download. 